\title{
O legado de Raymond Williams
}

\section{Maria Elisa Cevasco ${ }^{*}$}

A importaçào de idéias é parte inescapável da história intelectual brasileira. Sempre foi através de idéias fora do lugar que as determina que temos tentado compreender a realidade que nos cerca. Esse movimento, que começou muito antes de qualquer mençào a um debate multinacional em um espaço cultural globalizado, teve resultados positivos - de atualizaçào e esclarecimento do debate intelectual brasileiro - e também conseqüências nefastas, como nas ocasiōes em que se tenta aplicar modelos que explicam, ou ocultam, certas realidades à especificidade da situaçào nacional. De qualquer modo, é possivel generalizar e dizer que um bom critério para testar a relevância de idéias estrangeiras é confrontá-las com nossa realidade, e verificar se dào conta de explicar a situaçào de onde se originam, sua possibilidade de iluminar a nossa, e sua adequaçào a uma agenda de debate intelectual que se dirija a questòes reais e prementes da nossa situação.

Esse confronto está longe de ser tarefa fácil, mas é provavelmente o preço que é preciso pagar para tentar escapar da irrelevância. Nada disso é novidade, mas nào custa lembrar um pouco esse elemento estruturante do debate intelectual brasileiro neste momento, em que se desenrola o desembarque de mais uma forma de ler e explicar os produtos culturais, os estudos de cultura.

$\mathrm{Na}$ versào que chega ao Brasil nos anos 90, vinda, em especial, dos Estados Unidos, os estudos de cultura já vêm investidos de agenda própria. Nas palavras arrebatadas de um de seus praticantes mais conhecidos, Lawrence Grossberg, seu intuito é nada mais nada menos do que "politizar a teoria e teorizar a política". 1

Mesmo descontando o tom de jingle, ainda dá para ficar bastante animada, e mais se pensarmos na ordem de chegada dos modos de ler no Brasil. Os estudos de cultura vêm para suceder o pós-estruturalismo. Ao invés de desconstruir oposiçòes binárias, denunciar o logocentrismo, ou celebrar a disseminação e o significante, temos diante de nós a possibilidade de analisar todo o campo da significaçào. A

\footnotetext{
*Universidade de São Paulo

' Lawrence Grossberg. "The Cultural studies' Crossroads Blues". In: European Journal of Cultural Studies. v.1, n1. 1998, p. 65.
} 
cultura, ensinam os cultural studies, nào é formada apenas pelas grandes obras de arte. Ela deve ser entendida como o modo em que vivemos e construímos significados. A cultura é todo um sistema de comunicação que produz e reproduz significados e valores que têm o poder de mudar, para melhor ou para pior, a vida das pessoas. Vistos desse ângulo, os cultural studies trazem embutida uma promessa de relevância e intervençào que certamente tem muito para seduzir intelectuais pouco satisfeitos com a realidade que os cerca.

Mas, a mesma realidade que alimenta nossa insatisfação também determina os cultural studies. Este, aliás, um ponto de ligação fundamental entre os cultural studies versão anos 90 e a lógica do pós-estruturalismo. Sei que generalizar sobre o pósestruturalismo é tarefa complicada pela sua diversidade e volatilidade, mas penso que tanto os que o apreciam como ponto de chegada do projeto crítico da modernidade, como os que o detratam como sendo um mero replicante da lógica do sistema que pensa criticar, concordariam que sua característica mais marcante é a crítica do que se chama meta-narrativa e a correspondente valorização do aleatório e do heterogêneo. Vedar qualquer noçào de uma característica geral ou sistêmica que determine todos os fenômenos é uma característica estrutural dessa lógica. Este continua, a meu ver, a ser um elemento chave na produçào dos cultural studies contemporâneos.

Digo isso, e já incorporo o mencionado impedimento teórico da generalização: certamente há uma enorme produção que se identifica como "cultural studies", e é difícil, sem arrasar diferenças, captar elementos gerais. A bibliografia sobre o assunto é vasta e cresce em progressào geométrica. Uma das formas prediletas de veiculaçào dos cultural studies é através dos Readers - extensíssimas obras que juntam as diferentes disciplinas, abordagens e posiçōes. Por sorte, e bem à propósito para ajudar a apresentar uma descrição sumária, há os posfácios, tentativas de captar os elementos comuns que definem esta corrente.

No pósfacio a uma das mais das renomadas dessas antologias, o Cultural studies: a Reader, publicado pela Routledge em 1992, um volume de mais de 700 páginas, coletando contribuiçòes de 40 professores de diferentes disciplinas, nacionalidades, etnias e gêneros, Angela MacRobbie elogia a nova textualidade da produção contemporânea, e aponta a direçào para o futuro. Penso que vale a pena citar por extenso sua conclusão, uma vez que a forma em que é apresentado o argumento é, como sempre ocorre com as formas, reveladora do impulso que a determina. Assim se expressa MacRobbie: 
Pode-se considerar que a questão da identidade vai levar adiante os estudos de cultura nos anos 90, agindo como uma espécie de guia de como as pessoas se vêem a si mesmas, não como sujeitos de classe, não como sujeitos da psicanálise, não como sujeitos da ideologia, não como sujeitos de textos, mas como agentes ativos, cujo sentido de identidade se projeta e se exprime em várias práticas culturais em expansão, incluindo textos, imagens e mercadorias. $^{2}$

Em nossos tempos de mercantilizaçào exacerbada e de expansào inédita de técnicas de marketing e de propaganda parece certo que os produtos culturais e as mercadorias formem e informem certos aspectos da construção da identidade. $O$ que me preocupa na formulaçào reveladora de Angela MacRobbie é a repetição dos "nào": os cultural studies têm o objetivo intervencionista de guiar como as pessoas se vêem, mas para isso têm que negar pelo menos duas das meta-narrativas mais influentes do nosso século, o marxismo e a psicanálise. Nessa nova versào, a identidade se formaria acima da ideologia, e seria livre de qualquer enquadramento textual. Trata-se, em uma palavra, de uma identidade pós-restriçào, formada através de, e para as mercadorias. Na formulaçào de McRobbie, mercadorias, imagens e textos são as únicas palavras isentas de sentido negativo, sendo poupadas dos "nào".

Segundo essa formulaçào, a nova disciplina deveria guiar a construçào de identidades que estào fora de qualquer limitaçào, identidades que podem circular por toda parte, identidades flutuantes. O slogan dos cultural studies contemporâneo poderia ser : "Abaixo a causalidade, viva o jogo livre das identidades ilimitadas."

Tudo isso é muito interessante, mas se sairmos um pouco do nível rarefeito da teoria e pensarmos na prática que ela descreve, a coisa se complica. Ao negar com veemência qualquer tipo de determinação ou restriçào, esta formulaçào deixa de reconhecer um fato básico da vida social: identidades, produtos culturais, modos de vida nào sào construídos em condiçòes livres, e essas condiçòes apresentam limites e exercem pressòes que nào desaparecem só porque intelectuais escolhem nào enxergá-las. Ao nào reconhecer os fatos, a teoria perde em pelo menos duas frentes: deixa de descrever o que existe, condenado-se à irrelevância, e deixa de

\footnotetext{
2Angela McRobbie. "Post-marxism and Cultural studies. A Post- Script." In: Lawrence Grossberg, C. Nelson, and P. Treichley. Cultural studies: A Reader. London/NewYork, Routledge, 1992, p. 730 .
} 
reconhecer a natureza da prática que descreve, arriscando-se a fazer asserçòes errôneas e, ainda pior, jogar água no moinho do que pretendia opor.

Se alguém acha eu estou sendo injusta com MacRobbie, basta lembrar outro trecho de seu posfácio, que ajuda a explicar muito do tom triunfalista dos cultural studies contemporâneos. Descrevendo a conjuntura onde se dào essas produçōes, ela conclui que os tempos estào melhores. Na sua avaliaçào,

o mervado livre oferece oportunidades para novas identidades emergentes e, além disso, o capital, no sentido homogêneo e absolutista no qual nós da esquerda costumávamos nos referir a ele, é uma entidade muito mais frágil e fragmentária. ${ }^{3}$

Difícil imaginar de que mundo ela está falando. Certamente no Brasil as identidades mais claramente emergentes estão longe de nos dar qualquer razão para comemorar. Penso, por exemplo, no número aterrador de excluídos, daqueles a que Robert Kurtz chama de sujeitos monetários sem dinheiro. Nào sou especialista na história do capital, mas nesse momento preciso de sua hegemonia quase inconteste, defini-lo como frágil e fragmentário prejudica irremediavelmente a colocaçào.

Se essa é a avaliaçào de conjuntura que embasa a nova política das identidades nào é de admirar que gire em falso, e exponha os cultural studies a críticas acerbas, vindas os que seriam os aliados naturais, os pensadores de esquerda. Assim, em um número recente da New Left Review, Slavoj Zikek fuzila:

Eintão nós nos engajamos em nossas lutas politicamente corretas, pelos direitos das minorias étnicas, dos gays e clas lésbicas, dos diferentes estilos de vida, e assim por diante, enquanto o capitalismo continua em sua marcha triunfante- e a teoria de cultura contemporânea, na forma do cultural studies, está prestando um grande serviço para o desenvolvimento irrestrito do capitalismo ao participar de forma ativa no esforro ideológico de torná-lo invisivet

Os cultural studies contemporâneos ficam assim tingidos da pecha de fazer o jogo do sistema que declaram opor. Nessa versào ultra-lights, parecem ter vindo

$\overline{{ }^{3} \text { Idem Ibidem, p. } 724 .}$

+ Slavov Zizek. "Multiculturalism: A New Racism?" .In: New Left Review. 225, September/October 1997, p.46. 
apenas para deslocar a literatura de seu lugar de carro chefe das manifestações da cultura, e transformar-nos a todos seus estudiosos em "corretores de identidades", cada um tentando "vender" sua particularidade numa serialidade que acaba ridicularizando uma luta em princípio justa de aceitação de diferenças.

É nesse contexto e pensando no fato da chegada dos estudos de cultura no Brasil, chegada claramente assinalada, para ficar no âmbito das iniciativas institucionais, pelo tema do último Congresso da Associação Brasileira de Literatura Comparada, em agosto de 98- Literatura Comparada=Estudos de Cultura?- que penso valer a pena recolocar o legado de Raymond Williams. E isso nào porque ache que seja possível "aplicar" sua versào de cultural studies no Brasil - a noçào de aplicar é estranha ao pensamento de Williams - mas porque penso que suas formulações colocaram questões e desafios que foram simplesmente deixados para traz. Recolocálos pode nos ajudar a imaginar uma agenda diferente para os cultural studies.

Já tentei apontar, em outra ocasião, os pontos de contato entre o trabalho de Williams e a grande tradiçào brasileira de crítica de cultura, representada por Antônio Cândido e Roberto Schwarz. ${ }^{5}$ Aqui vou me limitar a delinear alguns das lições que podemos reter do cultural studies segundo Raymond Williams.

De quebra, falar de Williams é perturbar um pouco os rituais de luto com que os estudos de cultura contemporâneos tentam enterrar a contribuição de um de seus fundadores. O esforço parece ser o de reconhecer sua contribuiçào inicial, mas de marcar bem que sua época já terminou. Nas palavras emblemáticas de um dos editores de uma antologia de textos sobre sua obra publicada em 1992. "Apesar de ter morrido há apenas 5 anos, ele pertence a outra época política." 6

Como no caso da dimensào política transformada em reivindicação de particularidades, temos nessa reação um outro exemplo de excesso de particularização, agora, a de nosso momento na história. De forma sumária, a conclusão seria mais ou menos assim: nosso momento é de crise única. Nesses tempos é impossível pensar em mudanças radicais, os próprios termos com que essa mudança era conceituada estào banidos, termos como totalidade, comunismo, luta de classes,

\footnotetext{
"Ver meu "Cultural Studies: A Brazilian Perspective." Working Papers in British Studies, n.1, 1997.

"Dennis Dworkin. "Cultural Studies and the Crisis of British Radical Thought." In: Leslie Roman and Dennis Dworkin (eds.). Views Beyond the Border Country. New York/ London, Routledge, 1992, p. 34.
} 
açào coletiva. Nào é mais possivel pensar a possibilidade de igualdade, nossa política deve ter como objetivo a articulaçào de identidades singulares. Em teoria da cultura não é de bom tom apresentar explicaçòes: nas palavras reveladoras de Gayatry Spivak, "Explicando excluímos a possibilidade do radicalmente heterogêneo"7. No passado ainda era possível fazer oposição, agora tudo que nos resta é nosso conformismo estridente.

Acontece que nào somos os únicos a viver momentos difíceis. O trabalho de Williams também se desenrolou em tempos de crise. Pode-se dizer que no seu momento fundante, os cultural studies representavam justamente uma tentativa de articular uma resposta de esquerda ao cataclisma representado pela revelaçòes das atrocidades cometidas durante o estalinismo na União Soviética, as novas polaridades instituídas pela Guerra Fria e, no caso da Grà-Bretanha, as alteraçòes na política de classes ocasionadas pelos primeiros passos de uma sociedade "consumista", passos facilitados pelos curtos tempos de bonanza econômica do segundo pós-guerra.

Que providências pode tomar um crítico de cultura nesse quadro? Williams, formado em English em Cambridge, apresentou nada mais nada menos do que uma reformulaçào teórica e disciplinar do seu campo de estudos. Na versào inglesa, cultura era alta cultura, de preferência a grande tradição da literatura inglesa. Açào cultural era, mesmo para pessoas mais bem-intencionadas, fundar uma espécie de estado do bem estar da cultura, e difundir os produtos da alta cultura entre todas as classes.

Em contraste com essa concepçào, Williams se apropriou da noçào antes mais corrente em antropologia, de cultura como um modo de vida justamente para demonstrar que cultura é algo comum, que inclui, além das grandes obras - modos de descoberta e de criaçào - os significados e valores que organizam a vida em sociedade. Dessa ótica, é possível estender a noçào de valor cultural para abranger, além da grande arte, a criaçào de novos princípios de organizaçào da vida social, como, de forma evidente, o princípio alternativo da solidariedade, que dá forma a outros tipos de monumentos de cultura, também eles contribuições para uma herança cultural comum. É nesse sentido, por exemplo, que as grandes instituiçòes onde se tenta colocar em prática idéias coletivas de desenvolvimento social, como os sindicatos, os partidos políticos e os movimentos cooperativos, sào uma realização da criatividade.

Gaytri Spivak. In Other Worlds: Essays on Cultural Politics. New York/London, Rouledge,
(1) 88, p. 105. 
Mais do que difundir grande, obras, uma política das artes embasada nesse conceito de cultura tem como objetivo a extensão: a idéia é abrir os canais, facilitar o acesso, sabendo muito bem que com isso se perderá o controle das interpretações. Não se trata mais de impingir valores, mas de abrir a possibilidade para sua discussão em termos mais equalitários.

Em educação, o esforço deve ser o de promover a "cultural literacy": abrir a possibilidade para que todos detenham o poder de interpretar signos e formas de organizaçào da cultura.

Williams estava muito atento para o fato de que vivemos em uma época de expansào dos meios de comunicaçào. Longe de lamentar essa expansão, a atitude mais comum entre os que gostariam de manter a vida cultural sem mudanças, ele dedicou parte de sua obra a pensar modos de usar os avanços tecnológicos para inverter o fluxo normal da produção cultural: um número pequeno de produtores controlando e impingindo sua versào de cultura, hoje em dia mais comumente a de lixo cultural, a uma massa de consumidores. Em especial em Towards 2000, Williams explora as possibilidades de aumento do número de produtores abertas por novas tecnologias como o cabo e as câmaras de vídeo. Ao contrário dos tecno-apologistas, Williams sabe muito bem que para efetivamente alcançar essa extensão, teríamos que escolher um "tipo diferente de organização econômica e, conseqüentemente, um outro tipo de organização social."

Não creio que tenhamos avançado muito na solução dos problemas da extensào e da democratizacào da produçào da cultura, elementos chave para a transformação da cultura de minoria - seja no sentido da elite seja no da minoria que produz uma versào específica e, no mais das vezes, perversa de cultura para as ditas massas - em uma cultura comum. Ao contrário uma das diferenças entre o momento dos cultural studies na Grà-Bretanha dos anos 50 e 60 e nosso momento de cultural studies globalizados é que hoje aprendemos a temer qualquer noção de comunidade, como se "comum" só pudesse significar uma homogeneização totalitária de qualquer tipo de diferença. Mas já em 1958 Williams enfatizava que uma cultura comum não é, do modo algum, uma cultura homogênea e reduzida a uma só versão. Terá necessariamente que ser uma cultura mais complexa, exigindo constante redefiniçào e ajuste.

Não se deve, porém ficar perdendo tempo imaginado como será essa cultura futura. Prever o futuro nào é tarefa do militante do presente: devemos, diz Williams, tentar garantir os meios de se conseguir chegar a uma noção de comunidade cultural. 
O que será dito ou vivido no futuro com esses meios nào pode ser, para desespero dos planejadores da cultura, dado de antemào. No momento já ajudaria bastante promover o conhecimento das relaçòes sociais que determinam os produtos culturais e aumentar a possibilidade crítica.

Como nenhuma entre as disciplinas institucionalizadas parecia ter como objetivo promover os meios que levassem a essa cultura comum, ou que dessem conta de considerar a cultura como um modo de produzir significados e valores que por sua vez contribuem para criar as pressòes e delimitar as possibilidades reais de vida em sociedade, Williams fundou os cultural studies, um campo para estudar as formas com que damos significado à experiência vistas como uma concretização de relaçòes sociais específicas.

Rememorando esse momento fundador, em uma palestra de 1986, Williams enfatiza que o ponto central dos cultural studies, sua contribuiçào teórica mais importante foi a insistência no fato de que "não é possível entender um projeto artístico ou intelectual sem entender também sua formação, a relaçào entre projeto e formação é sempre decisiva, e a ênfase dos cultural studies é que justamente que ele Jeva em conta os dois, sem se especializar em um ou outro." Não se trata de relacionar um produto artístico a seu contexto cultural mas de entender que o projeto e a formação são maneiras diferentes de dar forma material, ou seja, modos diferentes de descrever ou realizar o que são de fato disposiçòes comuns de energia e direção. ${ }^{8}$

Essa visào teórica dos produtos artísticos como materialização de uma formação sócio-histórica exige uma revisào dos modos de se descrever essas relaçòes. O ponto central de entrada para essa questào é o problema da determinação - não por acaso o mesmo problema que os cultural studies contemporâneos insistem em esquecer.

Já na obra de Williams ele ocupa um papel central. Em dos de seus primeiros ensaios, "Culture is Ordinary", ele já aponta as dificuldades de se estabelecer essas relações. Assinala a descrição marxista em voga então da base econômica subjacente e da superestrutura expressiva desta base, mas já ressalva que a noção é mais complexa do que a descrição sugere. Embora considerando que seu projeto se insere na tradição marxista, insiste que é preciso levar às últimas conseqüências a contribuição do materialismo histórico e acabar de vez com descriçòes idealistas. A metáfora da

${ }^{8}$ Raymond Williams. "The Future of Cultural Studies.". In: The Politics of Moderrnism: Against the New Conformists. London, Verso, 1980, p.152-3. 
base/superestrutura deixa espaço para a colocaçào das artes em um domínio separado, obscurecendo o fato de que a produção artística é ela mesma material. Para Williams é necessário complementar o legado de Marx. Decorre daí a formulação do materialismo cultural a que ele chega nos anos 70 e que define como uma posiçào teórica a respeito da cultura, vista como um processo de produção material e social, e das artes como o uso social de meios materiais de produção, como a linguagem, a consciência prática material, as técnicas específicas de escrita e até os meios de comunicaçào mecânicos e eletrônicos. ${ }^{9}$

Não há espaço aqui para detalhar a diferença que faz essa posição. Mas de entrada muda não só o que se estuda, mas como e para que se estuda. Produtos culturais são modos de produçào - e nào apenas de reproduçào - de significados e valores. Estudálos implica reconhecer que sào produtos de formaçòes sociais específicas, que a linguagem e a comunicaçào sào forças sociais formativas. Esses produtos concretizam relações sociais complexas que envolvem instituições, formas e convenções. Desde sempre, mas de forma cada vez mais explícita em nossos tempos de proliferação de meios de comunicação, estão envolvidos em processos de dominação e controle. De fato, a descrição de hegemonia para Williams é equivalente à da cultura:

Hegemonia então não é apenas o nivel articulado mais elevado da ideologia e nem suas formas de controle são aquelas comumente vistas como manipulação ou doutrinação. Trata-se de todo um conjunto de práticas e de expectativas, sobre toda nossa vida: nossos sentidos, a consignafão de nossas energias, nossas percep̧ões formadoras de nossa subjetividade e de nosso mundo. É um sistema vivido de significados e valores - constituido e constituinte - os quais, ao serem vivenciados como práticas, parecem confirmar-se reciprociamente. Desse modo constituem o sentido da realidade para a maior parte das pessoas em uma sociedade...e no sentido mais forte do termo, [constituem-se] em uma cultura, mas uma cultura que tem que ser vista com a vivência da dominação e da subordinação de certas classes sociais. ${ }^{10}$

Na conjunçào histórica atual, de uma sociedade cujas técnicas e abrangência dos modos de veiculaçào de imagens atingem um alto grau de desenvolvimento, a

\footnotetext{
${ }_{9}^{9}$ Ver a este respeito Problems in Materialism and Culture. London, Verso, 1980, p.243.

"' Raymond Williams. Marxism and Literature. Oxford, Oxford University Press, 1977, p 110 .
} 
análise e esclarecimento dessas formas pode se constituir em um modo eficiente de luta. Para Williams, há um trabalho fundamental a ser feito em relação à hegemonia cultural. Num ensaio de 1977, ele resume a tarefa aberta aos que nào estão satisfeitos com a situaçào como está:

"Acredito que o sistema de significados e valores que a sociedade capitalista gera tem que ser derrotado no geral e no detalhe através de um trabalho intelectual e educacional continuo. Este é um processo cultural a que denominei de a longa revolução, e, ao fąế-lo, eu tinha em mente que era uma parte das batalhas necessárias da democracia e da vitória eionômica da classe trabalhadora organizada."11

Nào se trata aí de uma hipóstase da cultura como o único modo de luta e nem do idealismo atroz de se pensar que somos nós, estudiosos de cultura, que vamos fazer sozinhos a revoluçào. Mas trata-se certamente de uma codificaçào teórica (e disciplinar - se lembrarmos que os cultural studies vêm dai) de uma percepçào da experiência da vida contemporânea, marcada pela expansào vertiginosa dos meios de comunicaçào e pela invasão, pelas necessidades da sociedade das mercadorias, de todas as esferas da vida humana, das mais amplamente políticas às mais estritamente pessoais, configurando o processo de aculturaçào abrangente que rege a vida pós-moderna.

Decorrem daí muito do potencial cognitivo e oposicionista dos cultural studies. Este potencial está evidente nas análises informadas e minuciosas que Williams faz de textos literários, de filmes, das formas dos anúncios ou das transmissòes de notícias pela TV. Sua posiçào abre um enorme campo para que se levem a efeito análises das formas e das formaçòes culturais. Entretanto, os cultural studies pósmodernos, escolherem outro caminho, deixando de lado o legado de Williams. Esta a razào circunstancial para lembrá-lo neste momento de entrada dos cultural studies no Brasil.

Nào quero dizer com isso que se imitarmos Raymond Williams estaremos solucionando o problema da relevância dos estudos de cultura no Brasil nesta virada de milênio. Nào foram bem explorados ainda muitos de seus pontos centrais, como pensar os modos de determinaçào dos produtos culturais, estimular a extensào da capacidade de interpretar esses produtos para aqueles a quem a interpretação da

"Raymond Williams."You are a Marxist, aren't you?". In: Raymond Williams. Resources of Hope. p.76. 
cultura tem sido historicamente negada, estudar modos de usar o desenvolvimento tecnológico de formas mais democráticas e inclusivas, demonstrar a hegemonia e suas falhas que abrem caminho para contestá-la. Penso que se formos importar cultural studies, pode ser mais produtivo reativar o legado de Williams do que embarcar em mais uma moda descolada de nossa realidade e das tarefas que ela impòe. Além do enfoque produtivo e da prática de análise cultural, a posiçào de Williams tem a vantagem adicional de se reconhecer empenhada e de resistir à dissolução da dimensào política que sempre ronda a crítica de cultura. No firm das contas, como diz Williams, mais do que discutir teoria, vale a pena esclarecer de que lado estamos. Ele termina assim seu último ensaio sobre para que serve uma teoria de cultura:

No fim das contas temos que enfrentar na teoria, como em todo o resto, o mesmo desafio, e dizerer este é nosso conteúdo, esta nossa afiliação, esta nossa intenção e este nosso trabalho; e agora diga - e isso vale também para nós - se você está favor ou contra cada um deles. ${ }^{12}$

12 Raymond Williams, "The Uses of Cultural Theory.". In: The Politics of Modernism: Against the New Conformists. p. 176. 